\title{
Definir y redefinir al inmigrante: análisis de su tratamiento lexicográfico en los diccionarios de la lengua española (España-Argentina, 1726-1910)
}

\author{
Mónica Baretta* \\ CONICET - Universidad Nacional de San Martín, Argentina
}

\begin{abstract}
Resumen
En este artículo nos proponemos examinar el modo en que el diccionario, en tanto instrumento discursivo, histórico e ideológico (Lauria 2010, 2011) ha intervenido en la construcción de sentido del objeto discursivo inmigrante. Así, este trabajo consiste en relevar y analizar diacrónicamente las diferentes acepciones lexicográficas que tuvieron la entrada inmigrante, los lexemas semánticamente próximos (emigrante, migrante, etc.) y los verbos vinculados a estos (emigrar, inmigrar, migrar) en los diccionarios de la lengua española editados en España y Argentina entre 1726 y 1910.

Atenderemos, en primer lugar, a la manera en que las condiciones de producción, ya sea inmediatas o en sentido amplio (Orlandi 2015), han determinado gran parte de las modificaciones históricas que experimentó el campo semántico de la inmigración en la lexicografía española durante el siglo XIX. En segunda instancia, reflexionaremos sobre el modo en que la producción local ha resignificado al inmigrante al iniciarse el siglo $\mathrm{XX}$, momento histórico clave en
\end{abstract}

* Para correspondencia, dirigirse a: Mónica Baretta (monicabaretta@gmail.com), UNSAM - Campus Miguelete, Escuela de Humanidades, Martín de Irigoyen 3100, CP. 1650 San Martín (Bs. As.), República Argentina. 
el que confluyen el fenómeno de la "inmigración de masas" y la conmemoración del Centenario de la Revolución de Mayo.

Palabras clave: inmigrante, inmigración, diccionario, lexicografía, Argentina.

DEFINE AND REDEFINE THE IMMIGRANT: ANALYSIS OF HIS

LEXICOGRAPHICAL TREATMENT IN THE Dictionaries OF THE SPANISH

LANGUAGE (SpAin-Argentina, 1726-1910)

Abstract

In this paper we attempt to examine the way the dictionary, as a discursive instrument, historical and ideological (Lauria, 2010, 2011) has intervened in the construction of the sense of the discursive object inmigrante. Thus, this work consists in reveal and analyse diachronically the different lexicographic meanings that the entry inmigrante, the semantically close lexemes (emigrante, migrante, etc.) and the linked verbs (emigrar, inmigrar, migrar) had in the Spanish language dictionaries edited in Spain and Argentina between 1726 and 1910.

We will consider, firstly, the way in which the production conditions, either immediately or broadly speaking (Orlandi, 2015), have largely determined the historical changes that the semantic field of immigration experienced in the Spanish lexicography during the XIX century. Secondly, we will reflect on the way that the local production has re-signified the immigrant at the beginning of the XX century, key historic moment when the "mass immigration" phenomenon and the commemoration of the Centenary of the Revolution of May come together.

Keywords: immigrant, immigration, dictionary, lexicography, Argentina.

Recibido: 28/07/18 Aceptado: 08/01/19 


\section{INTRODUCCIÓN ${ }^{1}$}

Los primeros diccionarios de los cuales se tenga registro fueron bilingües o plurilingües y surgieron para dar salida a las dificultades prácticas de interacción entre personas o sociedades que hablaban lenguas diferentes. Así, aparecieron los primeros registros de "equivalencias" de vocablos como respuesta a la necesidad objetiva de comprender el discurso comercial, guerrero, diplomático o religioso de otro pueblo. Esto es lo que Lara (1997) denomina lexicografía informativa, básicamente por su función puramente instrumental como herramienta de conocimiento práctico.

Sin embargo, a partir del siglo XVI comenzó a gestarse en Europa occidental un nuevo tipo de instrumento lingüístico: el diccionario monolingüe. En este siglo, la formación de las grandes patrias y de los imperios modernos trajo aparejada la comprensión de un sentimiento nacional, alentada por los procesos de unificación territorial y expansión colonialista. En ese marco, las incipientes naciones europeas llevaron adelante una progresiva reflexión sobre las lenguas maternas como mecanismo de autolegitimación frente al dominio medieval del latín, que posteriormente sería orientada y aprovechada por la política, ligada a las necesidades de los Estados nacionales nacientes ${ }^{2}$.

En ese contexto, Francia, Italia y España iniciaron un proceso de gramatización ${ }^{3}$ de sus "lenguas maternas" o de la variedad que cada nación consideraba culta como para erigirse en lengua nacional y esto sirvió para definir nuevos tipos de instrumentos lingüísticos, ya no en términos de utilidad informativa sino en un sentido ante todo simbólico. En primer lugar,

1 Avances de este trabajo fueron presentados en las VIII Jornadas Internacionales de Filología y Lingüística y II de Crítica Genética "Las lenguas del archivo" (La Plata, junio de 2017) bajo el título "¿Qué significa ser inmigrante? El fenómeno migratorio en los diccionarios de la lengua española (España-Argentina, 1803-1910)".

2 Anderson (1993) señala que no se trató, al menos al principio, de un proceso meditado y voluntario ligado a reivindicaciones nacionalistas, como ocurriría hacia el siglo XVIII. Por el contrario, el afianzamiento de las lenguas vernáculas se trató más bien de la consecuencia de un fenómeno relacionado fundamentalmente con dos cuestiones. Por un lado, con el acelerado desarrollo que, gracias a la consolidación del capitalismo moderno, adquirió la imprenta, que agotó rápidamente el reducido público lector de latín y comenzó a editar en lenguas vernáculas. En segundo lugar, ese proceso se aceleró gracias a la Reforma, que propició la traducción y popularización de los textos bíblicos, hasta ese momento solo accesibles en latín.

3 "[Por gramatización, se entiende el] proceso que conduce a describir y a instrumentar una lengua sobre la base de dos tecnologías que son todavía hoy los pilares de nuestro saber metalingüístico: la gramática y el diccionario" (Auroux 1992: 65). 
aparecieron gramáticas y ortografías de fuerte impronta normativa, tendientes a establecer cánones de representación formal de las lenguas que fijaran parámetros de corrección, pero el propósito central fue sobre todo equiparar, a través de un esfuerzo erudito, las lenguas maternas con el latín históricamente hegemónico. De acuerdo con Lara (1997) los diccionarios monolingües no aparecieron, entonces, como resultados naturales del interés por la información sobre las lenguas maternas, ni como efectos de una necesidad sentida por la comunidad lingüística en su conjunto. Por el contrario, surgieron como elaboraciones de un interés por las lenguas fundado en ciertos valores políticos, heroicos y literarios, y como creaciones simbólicas, a partir de argumentaciones eruditas y filosóficas correspondientes, en última instancia, con los intereses de los Estados nacionales.

En el marco de la formación y consolidación de los Estados nacionales occidentales y, por consiguiente, de la construcción de identidades nacionales, en las cuales la codificación en el plano del lenguaje resultó uno de los ejes centrales, nos interesa indagar en la manera en que los instrumentos lingüísticos definieron al inmigrante, qué lugar le dieron en tanto extranjero y cómo fueron mutando esas acepciones, al compás de las transformaciones políticas. En ese sentido, este artículo propone relevar y analizar diacrónicamente las diferentes acepciones lexicográficas que tuvieron la entrada inmigrante, los lexemas semánticamente próximos (emigrante, migrante, etc.) y los verbos vinculados a éstos (emigrar, inmigrar, migrar) en los diccionarios de la lengua española y de argentinismos, editados entre 1726 y 1910. El abordaje analítico se realizará sobre dos niveles: a) en el plano de la macroestructura, donde atenderemos a la nomenclatura, es decir, el lemario o inventario de voces que se define, $\mathrm{y} b$ ) sobre la microestructura, donde indagaremos en el conjunto de informaciones que en el artículo lexicográfico siguen a la entrada (formulación de los enunciados definidores, presencia de marcas de uso, inclusión de citas y ejemplos, e incorporación de observaciones etimológicas y enciclopédicas).

Atenderemos, en primer lugar, a la manera en que las condiciones de producción, ya sea inmediatas o en sentido amplio (Orlandi 2015), han determinado gran parte de las modificaciones históricas que experimentó el campo semántico de la inmigración en la lexicografía española durante el siglo XIX. En segunda instancia, reflexionaremos sobre el modo en que los diccionarios de argentinismos han resignificado al inmigrante al iniciarse el siglo XX, momento histórico clave en el que confluyen el fenómeno 
de la "inmigración de masas" y la conmemoración del Centenario de la Revolución de Mayo ${ }^{4}$.

\section{EL EMIGRADO EN LAS DEFINICIONES TEMPRANAS DEL DRAE}

Un estudio lexicográfico que analice las definiciones históricas de un determinado repertorio de voces en la lengua española nos conduce necesariamente a un relevamiento, al menos rápido, de las primeras producciones de la Real Academia Española. Fundada en 1713, publicó su primer diccionario, comúnmente conocido como Diccionario de Autoridades $^{5}$, en varios tomos entre 1726 y 1739. En esta obra, solo se consignan dos voces vinculadas al campo semántico de la inmigración: emigración y migratorio/ria:

\begin{tabular}{|c|c|c|}
\hline \multicolumn{3}{|c|}{ EMIGRACIÓN } \\
\hline DRAE & $1732^{6}$ & $\begin{array}{l}\text { f.f. Partida de un Lugár à otro, ù de una parte à otra. } \\
\text { Es voz puramente Latina, y sin ufo. Lat. Emigratio. } \\
\text { COMEND. fob. las } 300 \text {. Copl. 117. E como ya fueffe } \\
\text { llegado el tiempo de fu emigración, mandado por el } \\
\text { Papa Gregorio X que fueffe à Ludguno.... cayó malo } \\
\text { en el camino. }\end{array}$ \\
\hline
\end{tabular}

4 Nunes (2006) señala que abordar el diccionario desde una perspectiva discursiva implica reconocer la historicidad de los diferentes dominios que lo componen: los elementos paratextuales (títulos, prólogos, notas, apéndices, etc.), la macroestructura o nomenclatura y la microestructura (enunciados definidores, marcas de uso, citas y ejemplos, etc.). Considerar su historicidad significa analizar los sentidos de sus elementos en relación con otros dominios en el marco de un corpus más amplio. El análisis incluye, así, la observación de relaciones de intertextualidad y de interdiscursividad que constituyen el discurso lexicográfico.

5 Todos los diccionarios de la lengua española que se citan en este artículo (exceptuando los diccionarios de argentinismos) se encuentran digitalizados en: http://ntlle.rae.es/ntlle/ SrvltGUILoginNtlle. Las transcripciones aquí realizadas respetan la ortografía y sintaxis de los originales.

6 Real Academia Española (1732). Diccionario de la lengua castellana, en que se explica el verdadero sentido de las voces, su naturaleza y calidad, con las phrases o modos de hablar, los proverbios o refranes, y otras cosas convenientes al uso de la lengua [...]. Compuesto por la Real Academia Española. Tomo tercero. Que contiene las letras D.E.F. Madrid. Imprenta de la Real Academia Española por la viuda de Francisco del Hierro. 
MigRATORIO, RIA

\begin{tabular}{|l|c|l|}
\hline DRAE & $1734^{7}$ & $\begin{array}{l}\text { adj. Lo que fe muda de una parte á otra. Es voz Latina, } \\
\text { y tiene poco ufo. Lat. Migratorius. Migrans. FUN. Hist. } \\
\text { nat. lib. 1. Cap. 35. Es ave migratória, y viene á nofotros } \\
\text { en el tiempo del Otoño, como el Tordo. }\end{array}$ \\
\hline
\end{tabular}

Las ediciones que siguieron, en 1780 y 1783, mantuvieron las mismas voces y definiciones, solo omitiendo la salvedad de que tienen "poco uso", que aparecía en el Diccionario de Autoridades. La edición de $1791^{8}$ también mantuvo la definición de migratorio/ria, pero modificó la de emigración y la edición inmediatamente posterior, la de $1803^{9}$, es la que más cambios incorporó ya que no solo alteró las definiciones de estas voces sino que además agregó nuevas:

\begin{tabular}{|l|c|l|}
\hline \multicolumn{2}{|l|}{ EMIGRACIÓN } \\
\hline DRAE & $1791 ; 1803$ & $\begin{array}{l}\text { s.f. El abandono que hace una familia, pueblo, ó nación } \\
\text { de su pais para establecerse en otro. Emigratio. }\end{array}$ \\
\hline EMIGRADO, DA & 1803 & $\begin{array}{l}\text { adj. El que emigra. Úsase también como sustantivo. } \\
\text { Emigrans. }\end{array}$ \\
\hline DRAE & 1803 & $\begin{array}{l}\text { v.n. Dejar ó abandonar su propio país con ánimo de } \\
\text { domiciliarse, ó establecerse en otro extranjero. Emigrare. }\end{array}$ \\
\hline EMIGRAR & \multicolumn{2}{|l}{} \\
\hline DRAE & 18 RIA
\end{tabular}

7 Real Academia Española (1734). Diccionario de la lengua castellana, en que se explica el verdadero sentido de las voces, su naturaleza y calidad, con las phrases o modos de hablar, los proverbios o refranes, y otras cosas convenientes al uso de la lengua [...]. Compuesto por la Real Academia Española. Tomo quarto. Que contiene las letras G.H.I.J.K.L.M.N. Madrid. Imprenta de la Real Academia Española, por los herederos de Francisco del Hierro.

8 Real Academia Española (1791). Diccionario de la lengua castellana compuesto por la Real Academia Española, reducido a un tomo para su más fácil uso. Tercera edición, en la qual se han colocado en los lugares correspondientes todas las voces de los suplementos, que se pusieron al fin de las ediciones de los años de 1780 y 1783 , y se han intercalado en las letras D.E. y F. nuevos artículos, de los quales se dará un suplemento separado. Madrid. Viuda de Joaquín Ibarra.

9 Real Academia Española (1803). Diccionario de la lengua castellana compuesto por la Real Academia Española, reducido a un tomo para su más fácil uso. Quarta edición. Madrid. Viuda de Ibarra. 


\begin{tabular}{|l|l|l|}
\hline DRAE & 1803 & $\begin{array}{l}\text { adj. p. us. Lo que se muda de una parte á otra. } \\
\text { Migratorius, migrans. }\end{array}$ \\
\hline
\end{tabular}

Entre 1791 y 1803 , se advierten dos grandes modificaciones. En primer lugar, con respecto al espacio: a diferencia de las tres primeras ediciones del DRAE (Autoridades 1780 y 1783) que refieren como "parte" o "lugar" a ese espacio geográfico desde el cual se produce la partida o mudanza, la edición de 1791 reemplaza "lugar" por "país" en la definición de emigración. Si bien esta modificación puede leerse como una opción más precisa, ligada a las reestructuraciones espaciales y limítrofes que se estaban produciendo en Europa, no debe perderse de vista que la definición misma de país estaba, en esos mismos diccionarios y a lo largo de todas las ediciones del siglo XIX y XX, cargada de gran vaguedad ${ }^{10}$ :

\begin{tabular}{|l|l|l|}
\hline \multicolumn{3}{|l|}{ PAis } \\
\hline DRAE & 1803 & s.m. Region, reyno, provincia ó territorio. Regio. \\
\hline
\end{tabular}

De cualquier manera, y aunque con cierta imprecisión, circunscribir la acción de emigrar desde un espacio geográfico como una región, reino, provincia o territorio, ciñe de alguna manera la acción a una actividad y a un propósito humanos: el ánimo de establecerse o domiciliarse en otro ámbito. Esto va de la mano con el segundo cambio introducido entre 1791 y 1803: se incorpora un agente para la emigración ("una familia, pueblo o nación") y se agregan el verbo emigrar y el adjetivo/sustantivo emigrado/ $d a$ para designar a ese agente ${ }^{11}$.

El vocablo emigrado, por su parte, llega al español como traducción del francés emigré, acuñado por l'Academie Française en $1798^{12}$ para referir a quienes huían de Francia durante los años posteriores a 1789, perseguidos por las autoridades revolucionarias. España fue uno de los principales destinos

10 Actualmente, las primeras dos acepciones de la entrada país en el Diccionario de la RAE son: "1. m. Territorio constituido en Estado soberano. 2. m. Territorio, con características geográficas y culturales propias, que puede constituir una entidad política dentro de un Estado". Hasta el año 1992, no obstante, la definición continuó prácticamente sin alteraciones con respecto a la que aparece en el diccionario de 1803.

11 La acepción de Migratorio, ria quedaría de allí en adelante separada de la praxis humana ("lo que se muda...") y hacia 1869 comenzará a definirse como una actividad propia de las aves migratorias: “adj. Lo relativo á los viajes periódicos de las aves de paso, ó á las especies que los hacen” (DRAE 1869).

12 Le Dictionnaire de l'Académie Française, 5ème édition, 1798. Disponible en: http:// portail.atilf.fr/dictionnaires/ACADEMIE/index.htm 
para este grupo de emigrés, con lo cual el sustantivo emigrado se introdujo para referirse a ellos poco después de su arribo (Fuentes 2002):

\begin{tabular}{|l|l|l|}
\hline \multicolumn{2}{|l|}{ ÉMIGRÉ, ÉE } \\
\hline $\begin{array}{l}\text { Dictionnaire } \\
\text { de L'Académie }\end{array}$ & 1798 & $\begin{array}{l}\text { sub. se dit particulièrement des François qui, sans y être } \\
\text { autorisés, sont sortis de France depuis la Révolution, et } \\
\text { Française }\end{array}$ \\
\hline
\end{tabular}

En Francia eran émigrés porque habían emigrado, se habían ido fuera del país: el prefijo latino é- indica "fuera de" y migrar, del latín migrāre, "trasladarse, moverse". Pero España, que los recibe y experimenta el proceso de manera especular, no modifica ese prefijo por su opuesto (in-: "hacia el interior", "dentro de") sino que realiza una traducción literal del término, al margen de la posición material del enunciador que había determinado el prefijo original en francés $(e ́-)$.

Las entradas emigración, emigrado/da, emigrar y migratorio/ria se mantienen sin cambios en las ediciones siguientes: 1817, 1822, 1832 y 1837. Sin embargo, y a pesar del antecedente político que había dado origen a la voz emigrado en la lengua francesa, es recién a partir de la edición del DRAE de $1843^{14}$ cuando estos términos son asociados a "circunstancias políticas":

\begin{tabular}{|l|l|l|}
\hline Emigración \\
\hline DRAE & 1843 & f. El acto y efecto de emigrar. Emigratio. \\
\hline Emigrar & 1843 & $\begin{array}{l}\text { n. Dejar o abandonar una familia o nación su propio } \\
\text { país con ánimo de domiciliarse ó establecerse en otro } \\
\text { extranjero. Emigrare. Hoy se aplica mas bien al que } \\
\text { toma este partido obligado por circunstancias políticas. } \\
\text { DRAE }\end{array}$ \\
$\begin{array}{l}\text { El participio pasivo de este verbo se usa también como } \\
\text { sustant }\end{array}$ \\
\hline
\end{tabular}

13 "Se dice particularmente de los franceses que, sin estar autorizados, han salido de Francia después de la Revolución, y que no han regresado dentro del período estipulado por la ley".

14 Real Academia Española (1843). Diccionario de la lengua castellana por la Real Academia Española. Novena edición. Madrid. Imprenta de D. Francisco María Fernández.

15 La entrada emigrado, que como indicamos aparece en las ediciones de 1803, 1817, 1822, 1832 y 1837, es suprimida temporariamente en las ediciones de 1843,1852 y 1869 . En las primeras cinco apariciones, es definida como adjetivo, aunque aclarando que también puede funcionar como sustantivo: "adj. El que emigra. Úsase también como sustantivo. Emigrans" (DRAE 1803: 920). Las ediciones que omiten esta entrada aclaran en la definición de emigrar que "El participio pasivo de este verbo se usa también como sustantivo" (DRAE 1843: 281). 
Hacia 1843, el DRAE comienza a definir la acción de emigrar como producto de la obligación de las "circunstancias políticas". ¿Por qué España incorpora ese factor en este momento y no antes, si ya los franceses habían sido emigrados como resultado de la persecución post-revolución? A partir de 1814 la emigración política fue un fenómeno recurrente en Europa, en general, y en España, en particular, por sucesivas guerras civiles, pronunciamientos e insurrecciones armadas que provocaron el éxodo masivo hacia otros países europeos, debido a la fuerte presión que los distintos gobiernos ejercieron sobre sus opositores: los afrancesados y liberales abandonaron España siguiendo la retirada de Napoleón al restituirse la monarquía de Fernando VII (1814), los absolutistas se marcharon luego de fracasar en la contrarrevolución de 1822, durante el llamado "Trienio Liberal" (1820-1823) y los constitucionalistas liberales se exiliaron durante la llamada "Década Ominosa" (1823-1833) (Fuentes 2002). Así, la figura del emigrado y la acción de emigrar quedaron lexicográficamente vinculadas en el español a aquel que abandonara su país obligado por las circunstancias políticas, recién cuando el fenómeno afectó a la población española ${ }^{16}$.

\section{LOS DICCIONARIOS DE AUTOR Y LA INCORPORACIÓN DEL INMIGRANTE}

Como hemos señalado, durante más de 100 años de lexicografía española (1726/1739-1843) solo se consignó el acto de irse (prefijo e-: emigrar, emigración, emigrado), sin considerar el proceso inverso y especular que produce el fenómeno de desplazamiento de personas o grupos de personas: si una familia, pueblo o nación emigra al mismo tiempo inmigra. Sin embargo, las voces inmigración, inmigrar y migración aparecen por primera vez un par de décadas después, en el diccionario de Gaspar y Roig de $1855^{17}$ :

16 Sobre este punto, recordamos que, en el ámbito rioplatense, los argentinos que durante el régimen rosista huyeron del país debido a la persecución política hacia los opositores, se autodenominaron emigrados, término que coexistía en sus escritos con otros parcialmente equivalentes como desterrados o proscriptos (Devoto 2004).

17 Gaspar y Roig (1855). Diccionario enciclopédico de la lengua española, con todas las vozes, frases, refranes y locuciones usadas en España y las Américas Españolas [...] Tomo II, Madrid, Imprenta y Librería de Gaspar y Roig. 


\begin{tabular}{|l|l|l|}
\hline \multicolumn{2}{|l|}{ INMIGRACIÓN } & $\begin{array}{l}\text { Gaspar y } \\
\text { Roig }\end{array}$ \\
\hline INMIGRAR & 1855 & $\begin{array}{l}\text { s.f. establecimiento de estranjeros en un país; es lo } \\
\text { contrario de emigración. }\end{array}$ \\
\hline $\begin{array}{l}\text { Gaspar y } \\
\text { Roig }\end{array}$ & 1855 & $\begin{array}{l}\text { v.n. ir a establecerse en un país: se usa por oposición } \\
\text { a emigrar. }\end{array}$ \\
\hline MigRACIÓN & $\begin{array}{l}\text { V. EMIGRACIÓN: la traslación de un país a otro para fijar en } \\
\text { él su residencia. Se aplica a las emigraciones históricas } \\
\text { que han hecho razas y pueblos enteros. También se dice } \\
\text { hablando de las aves de paso. }\end{array}$ \\
\hline $\begin{array}{l}\text { Gaspar y } \\
\text { Roig }\end{array}$ & 1855
\end{tabular}

El diccionario de Gaspar y Roig forma parte de lo que se denomina diccionarios particulares, comerciales o diccionarios de autor, es decir, producciones lexicográficas ajenas a la Real Academia Española o a las academias oficiales de otros países, cuyas publicaciones se consideran académicas o corporativas $^{18}$. Al comenzar el siglo XIX, la consolidación de las instituciones burguesas, la proliferación de los órganos de prensa y la ampliación del público letrado, entre otros factores, provocaron que la sociedad "se apropiara" de la lengua y ésta dejara de ser potestad única de la corte. Así, la lexicografía española (aunque también la inglesa y la francesa) salió del patronato del Estado y pasó a los particulares: a las casas editoriales y a los lexicógrafos que les vendían su trabajo (Lara 1997).

A diferencia de las obras académicas, cuya preocupación tenía que ver sobre todo con una erudición literaria más orientada a la celebración de la lengua que a su enseñanza, los diccionarios particulares venían a responder a las necesidades de la burguesía. Para este nuevo grupo social, el diccionario se convertía en una obra verdaderamente pedagógica, que ponía a su disposición una "lengua correcta" a la que se llegaba como resultado de la conquista del espacio público. Lara (1997) señala que estos nuevos instrumentos lexicográficos adquirieron un claro valor didáctico al ser producidos por la burguesía y para la burguesía: la autoridad ya no venía de afuera, sino que se generaba en el solo hecho de que allí se volcaba el vocabulario compartido por esta clase, vocabulario aceptado como propio por

18 Información detallada sobre las tipologías de diccionarios y sus características puede verse en Lauria (2010: 18-21). 
ella misma. No es extraño, entonces, que hayan sido estas obras aquellas que se anticiparon a recoger nuevas voces y a incluirlas dentro de su repertorio ${ }^{19}$.

Sin embargo, a pesar de incorporarse las voces inmigración, inmigrar y migración, éstas son definidas en Gaspar y Roig por oposición a emigración y emigrar, que siguen funcionando como patrones a partir de los cuales se disponen las demás definiciones ("es lo contrario de emigración"; "se usa por oposición a emigrar"). Esta perspectiva cambia con la siguiente edición del DRAE de $1869^{20}$, que incorpora los términos inmigración, inmigrar y migración con las siguientes definiciones:

\begin{tabular}{|c|c|c|}
\hline \multicolumn{3}{|c|}{ INMIGRACIÓN } \\
\hline DRAE & 1869 & f. La acción y efecto de inmigrar. \\
\hline \multicolumn{3}{|c|}{ INMIGRAR } \\
\hline DRAE & 1869 & $\begin{array}{l}\text { n. Trasladarse a una región para establecerse en ella, los } \\
\text { que estaban domiciliados en otra. Se dice especialmente } \\
\text { de los que pasan a formar nuevas colonias, ó a } \\
\text { naturalizarse en las ya formadas. }\end{array}$ \\
\hline \multicolumn{3}{|c|}{ MigRACIÓN } \\
\hline DRAE & 1869 & $\begin{array}{l}\text { V. EMIGRACión || La acción y efecto de pasar de un país } \\
\text { a otro para establecerse en él. Se dice hablando de las } \\
\text { históricas que han hecho las razas ó los pueblos enteros. } \\
\| \text { Se aplica también a las de las aves de paso. }\end{array}$ \\
\hline
\end{tabular}

A diferencia de Gaspar y Roig, el DRAE no define los términos por oposición, sino que les otorga un significado autónomo, asociándolo a un fenómeno que trasciende las fronteras europeas: "Se dice especialmente de los que pasan a formar nuevas colonias, ó a naturalizarse en las ya formadas". Atendemos, en ese sentido, a las definiciones siguientes:

19 Rodríguez Barcia señala que "el sometimiento por parte de los académicos pioneros a la intención de recoger la lengua en su momento álgido conllevó también purismo y puritanismo. Por poner un ejemplo concreto, la realidad construida y proyectada por la RAE pecaba durante los primeros años de trabajo de la institución de manifestar cierto carácter puritano y acusaba la ausencia de voces que se consideraban obscenas o contrarias al buen gusto. De hecho, durante el siglo XIX constituyó una práctica común la publicación de vocabularios que trataban de completar los trabajos académicos" (2011: 466).

20 Real Academia Española (1869). Diccionario de la lengua castellana por la Real Academia Española. Undécima edición. Madrid, Imprenta de Don Manuel Rivadeneyra. 


\begin{tabular}{|l|c|l|}
\hline COLONIA & 1869 & $\begin{array}{l}\text { f. Cierta porcion de gente que se envía, de órden de } \\
\text { algun príncipe o república, á establecerse en otro país, } \\
\text { y tambien el sitio ó lugar donde se establecen. }\end{array}$ \\
\hline COLONIZACIÓN & 1869 & f. El acto ó efecto de colonizar. \\
\hline DRAE & 1869 & a. Formar ó establecer colonia en algun país. \\
\hline COLONIZAR & & $\begin{array}{l}\text { m. El que habita en alguna colonia. } \| \text { El labrador que } \\
\text { cultiva y labra alguna heredad por arrendamiento, y } \\
\text { vive en ella. }\end{array}$ \\
\hline DRAE & 1869 &
\end{tabular}

La edición del DRAE de 1884 mantiene las definiciones de 1869, con la única salvedad de modificar las acepciones para la entrada colonia, ligándola de manera específica al proceso de colonización agrícola:

\begin{tabular}{|l|l|l|}
\hline \multicolumn{2}{|l|}{ Colonia } & \multicolumn{2}{|l|}{1884} & $\begin{array}{l}\text { (Del lat. colonia; de colōnus, labrador) f. Número más o } \\
\text { menos considerable de personas que va de un país a otro } \\
\text { para poblarle y cultivarle, ó para establecerse en él. || País } \\
\text { o lugar donde se establece esta gente. || País o territorio } \\
\text { más o menos distante de la nación que le hizo suyo, y } \\
\text { ordinariamente regido por leyes especiales. || Gente que } \\
\text { se establece en un territorio inculto de su mismo país } \\
\text { para poblarle y cultivarle. } \| \text { Este territorio. \| Cinta de } \\
\text { seda, lisa, de dos dedos de ancho, poco más o menos. }\end{array}$ \\
\hline
\end{tabular}

El incipiente proceso migratorio transatlántico que comienza a producirse en la década de 1850 es lo que motivaría, a partir de 1869, la formulación de una definición autónoma para las voces inmigración e inmigrar, despegándolas definitivamente de los móviles políticos asociados a emigrar y emigración, y enlazándolas al campo semántico de la colonización agrícola.

Recordemos, aquí, las campañas de propaganda que en la prensa europea realizaron los gestores de los primeros emprendimientos de colonización agrícola en la Argentina, para atraer interesados. Esto demuestra que en España y en los países vecinos los llamados "agentes de inmigración" comenzaron a tener una visibilidad y circulación que puso de manifiesto la especularidad del proceso. Aaron Castellanos, empresario argentino impulsor y gestor de la formación de Esperanza, la primera colonia agrícola organizada 
del país, se había encargado de distribuir propaganda propia en Alemania, Suiza y Francia para reclutar inmigrantes. Esto provocó el descontento de agencias locales que monopolizaban el negocio de la venta de pasajes transatlánticos, por lo que Castellanos y su proyecto fueron difamados en los periódicos y los agentes distribuyeron folletos en las iglesias de las aldeas (Djenderedjian, Bearzotti y Martirén 2010). Este caso ilustrativo muestra de qué manera, hacia la década de 1850, la inmigración era un tema corriente en el ámbito europeo: la información de los agentes de promoción y reclutamiento circulaba de boca en boca, en la prensa, en la iglesia, en la plaza o en la mesa familiar. Devoto (2004) señala que, hacia fines del siglo XIX, solo en Italia se registraba la presencia de al menos 20.000 agentes: un verdadero ejército de difusión.

Inmigrar es entonces, hacia 1869, "pasar a formar nuevas colonias o naturalizarse en las ya formadas" y colono es aquel que "habita en alguna colonia" y/o labra la tierra en la que vive. Si bien el término inmigrante aún no se había consignado en los diccionarios, esta proximidad semántica entre inmigrar y colonizar atribuye de manera indirecta un rasgo al sujeto que inmigra: la condición de trabajador rural.

\subsection{ZEROLO, LEXICÓGRAFO E INMIGRANTE}

En el año 1895 se incluye por primera vez en un diccionario del español la entrada inmigrante, nuevamente por iniciativa de un diccionario particular: el Diccionario enciclopédico de la lengua castellana de Elías Zerolo ${ }^{21}$. Esta obra, que cuenta con la co-autoría de otros dos lexicógrafos (el español Miguel de Toro y Gómez y el colombiano Emiliano Isaza) "y otros autores españoles y americanos", contiene las voces, frases, refranes y locuciones de uso corriente en España y América. Además, en su carácter de enciclopédica, la publicación incluye referencias biográficas, nombres propios, ilustraciones, retratos, mapas, etc. Allí se define:

21 Zerolo, Elías (1895). Diccionario enciclopédico de la lengua castellana. París, Garnier Hermanos. Hacia fines del siglo XIX, en pleno período de restauración borbónica iniciado en 1874, gran cantidad de intelectuales españoles se exiliaron en Francia. Esta situación, sumada a la reciente emancipación de las antiguas colonias americanas que habían roto lazos políticos y comerciales con España, facilitó el desarrollo de una lexicografía española con sede en París (Trujillo González 2013). 


\begin{tabular}{|l|l|l|}
\hline \multicolumn{2}{|l|}{ INMIGRACIÓN } \\
\hline Zerolo & 1895 & f. La acción y efecto de inmigrar. \\
\hline INMIGRANTE \\
\hline Zerolo & 1895 & p.a. de INMIGRAR y s. que inmigra. \\
\hline INMIGRAR & 1895 & $\begin{array}{l}\text { (Del lat. Immigrare; de in, en, y migrare, irse, pasar.) n. } \\
\text { Trasladarse á una región para establecerse en ella los que } \\
\text { estaban domiciliados en otra. Se dice especialmente de } \\
\text { los que pasan á formar nuevas colonias, ó á naturalizarse } \\
\text { en las ya formadas. Observación: Rige la preposición } \\
\text { EN. }\end{array}$ \\
\hline
\end{tabular}

El diccionario de Zerolo es el primero en incorporar la voz inmigrante y eso coincide con una particularidad histórica: su autor vivió en la Argentina, en condición de inmigrante, al menos entre 1872 y 1874. Según las escasas fuentes biográficas existentes, se conoce que, en 1871, Elías Zerolo (que había nacido en las Islas Canarias en 1849) se trasladó con su familia desde Sevilla hacia América del Sur y hasta 1876 vivió en la Argentina, Uruguay y Brasil. Luego regresó a Europa y desde 1882 se instaló definitivamente en París hasta su muerte en 1900 (Medina López 2007; Guimerá Peraza 1996). Durante su estancia en América, Zerolo estuvo radicado en Azul (provincia de Buenos Aires, Argentina) al menos entre 1872 y 1874, localidad en la que tuvo un gran protagonismo social y cultural: fue miembro de la logia masónica "Estrella del Sud" y participó de la Sociedad de Instrucción y Recreo "La Cosmopolita", institución de la que fue presidente en 1874. En el año 1872 impulsó la creación de una biblioteca popular en esa localidad, acontecimiento que le valió el reconocimiento del intendente local ${ }^{22}$.

Es decir que Zerolo no solo fue un inmigrante europeo en la Argentina, sino que además tuvo gran participación social y política en la comunidad en la que vivió, justo durante el período "caliente" en el cual el gobierno nacional discutía la Ley $\mathrm{N}^{\circ} 817$ de Inmigración y Colonización, sancionada en 1876. Consideramos, en ese contexto, que ese lugar social le permitió ponerse en contacto con la noción de inmigrante, con seguridad presente no solo en el habla de la comunidad inmediata sino además en la prensa que indefectiblemente se haría eco del fenómeno inmigratorio y del debate público previo a la Ley $\mathrm{N}^{\circ} 817$.

22 Fuente: http://logiaestrelladelsud.blogspot.com.ar/ (consultado en febrero de 2017). 
Consideramos, así, que las condiciones de producción inmediatas de este diccionario, entendiendo por ello el contexto histórico y material del autor de la obra, en el cual su trayectoria y sus redes sociales ocupan un lugar privilegiado, son las que motivan la incorporación de una voz hasta el momento no consignada en ningún otro diccionario: inmigrante. De la misma manera, el conocimiento material y de primera mano que Zerolo tenía por haber vivido en la Argentina explicaría la incorporación de ciertos artículos geográficos en su obra, que posiblemente por su irrelevancia demográfica, no habían sido consignados en otros diccionarios enciclopédicos ${ }^{23}$ : "ESPERANZA. Geogr. Importante colonia agrícola de la prov. de Santa Fe (Rep. Argentina) situada a $38 \mathrm{~km}$. al NO de su cap. Tiene 5.000 habitantes" (Zerolo 1895: 1001); “Azul. (El). Partido de la prov. de Buenos Aires (Rep. Argentina). Sup. 6.407 km cuad. y 18.000 hab." (Zerolo 1895: 312) 24. $^{24}$

Luego de la publicación del diccionario de Zerolo, el DRAE recoge la voz inmigrante y la incorpora por primera vez en su edición inmediatamente posterior $(1899)^{25}$, pero además reacomoda las definiciones de las demás entradas del siguiente modo:

\begin{tabular}{|l|l|l|}
\hline EMIGRACIÓN \\
\hline DRAE & 1899 & [Del lat. emigratio $]$ f. Acción y efecto de emigrar. \\
\hline EMIGRADO, DA \\
\hline
\end{tabular}

23 Cfr. Toro y Gómez, M. de (1901). Nuevo diccionario enciclopédico ilustrado de la lengua castellana. París - Madrid, Librería Armand Colin - Hernando y Cía. Sin embargo, en el año 1918 se publica una obra que recoge ambos artículos con la misma acepción que les había dado Zerolo: Rodríguez Navas y Carrasco, M. (1918). Diccionario general y técnico hispano-americano. Madrid, Cultura Hispanoamericana.

24 Rodríguez Barcia $(2011,2012)$ señala que el análisis del discurso lexicográfico debe atender de manera privilegiada a la noción de autoría y de contexto histórico. Observa, en este sentido, que resulta pertinente para el analista "tener información acerca de la competencia comunicativa del autor, así como de su background personal, su biografía y la comunidad epistémica en la que se ha desarrollado para conocer al menos en parte su background cultural común (2012: 145). Subraya, además, que "la definición lexicográfica-que, grosso modo, tendría que limitarse a presentar una suma distintiva de semas denotativos-se convierte en las manos de cualquier redactor en un enorme problema desde el punto de vista de la manifestación ideológica. El trasfondo, el background cultural común, las vivencias y experiencias particulares, las filias y fobias del redactor y su competencia comunicativa ideológica resultan determinantes para la construcción de una realidad a su medida, a la medida de la institución a la que pertenece dicho redactor y del mundo que unos y otros han aprehendido" (2011: 465).

25 Real Academia Española (1899). Diccionario de la lengua castellana por la Real Academia Española. Décimatercia edición. Madrid. Imprenta de los Sres. Hernando y compañía. 


\begin{tabular}{|l|c|l|}
\hline DRAE & 1899 & $\begin{array}{l}\text { m. El que reside fuera de su patria, obligado a ello por } \\
\text { circunstancias políticas. }\end{array}$ \\
\hline EMIGRANTE & \multicolumn{2}{|l|}{} \\
\hline DRAE & 1899 & p.a. de Emigrar. Que emigra. U.t.c.s. \\
\hline EMIGRAR & 1899 & $\begin{array}{l}\text { (Del lat. emigrare) n. Dejar o abandonar una persona, } \\
\text { familia o nación su propio país con ánimo de domiciliarse } \\
\text { ó establecerse en otro extranjero. }\end{array}$ \\
\hline DRAE & 1899 & \begin{tabular}{l} 
f. Acción y efecto de inmigrar. \\
\hline Inmigración
\end{tabular} \\
\hline DRAE & 1899 & \begin{tabular}{l} 
p.a. de InMIGRAR. Que inmigra Ú.t.c.s. \\
\hline Inmigrante
\end{tabular} \\
\hline DRAE & 1899 & $\begin{array}{l}\text { (Del lat. Immigrare; de in, en, y migrare, irse, pasar.) n. } \\
\text { Llegar a un país para establecerse en él los que estaban } \\
\text { domiciliados en otro. Se dice especialmente de los } \\
\text { que forman nuevas colonias, ó se naturalizan en las ya } \\
\text { formadas. }\end{array}$ \\
\hline Inmigrar &
\end{tabular}

El cambio de 1899 se mantiene en todas las ediciones del siglo XX (1914, 1925, 1939, 1947, 1956, 1970, 1984, 1992 ${ }^{26}$ del DRAE: se reserva la voz emigrado para aquel que vive en un país distinto al de su nacimiento obligado por circunstancias políticas, e incorpora emigrante para aquel que emigra. Asimismo, inmigración, inmigrante e inmigrar permanecen, a lo largo de todo el período, vinculados a la formación de nuevas colonias o al asentamiento en las ya existentes, fijándole al objeto inmigrante el atributo de 'colono' o 'trabajador rural' ${ }^{27}$.

26 Las ediciones del siglo XXI (2001 y 2014) modifican estas entradas, pero hemos decidido descartarlas del análisis por exceder ampliamente nuestro recorte temporal.

27 Esta definición de mantendría hasta la edición de 1927, cuando el DRAE recorta la acepción de inmigrar, despegándola del fenómeno de la colonización agrícola: "Inmigrar. intr. Llegar a un país para establecerse en él" (DRAE 1927: 1109). 


\section{EL NACIONALISMO DEL 900 DEFINE Y UBICA AL INMIGRANTE, AGENTE DE DESORDEN}

En Argentina, la producción lexicográfica monolingüe del español se inició, en términos estrictos, en la primera mitad del siglo XIX con la publicación del Vocabulario rioplatense de Francisco J. Muñiz, en 1845. Pero fue solo a partir de 1870 y hasta el Centenario de la Revolución de Mayo, en 1910, cuando se intensificaron las instancias planificadoras del lenguaje con la proliferación de instrumentos lingüísticos de diversa índole: diccionarios, manuales escolares, gramáticas, etc. Siguiendo a Lauria (2010) entendemos este fenómeno en el marco de un doble proceso: por un lado, la etapa de formación y consolidación del Estado nacional que, análogamente al caso europeo, necesariamente abrió un período de planificación, ordenamiento y codificación en distintos frentes institucionales (educativo, jurídico, económico), y por otro lado, el crecimiento acelerado del movimiento inmigratorio que conllevó un aumento de la diversidad lingüística, social y cultural, motivando al Estado (o a miembros de sectores de la sociedad civil afines a las clases dirigentes) a intervenir en el dominio simbólico del idioma, con el fin de construir un espacio cultural y lingüísticamente homogéneo.

En ese marco, a partir de 1879 se produjeron numerosos instrumentos lexicográficos que registraron las singularidades léxicas de esta región de la América hispánica. Así, se publicaron obras de índole descriptiva que registraban ruralismos, indigenismos y regionalismos, y además se editaron materiales con una vigorosa impronta normativa que daban cuenta de barbarismos y vulgarismos, censurando su uso al tomar como parámetro la norma del castellano de Madrid (Lauria 2011). Sin embargo, fue recién durante los primeros años del siglo XX cuando se editaron los primeros dos diccionarios de argentinismos $^{28}$ : el Diccionario argentino de Tobías Garzón,

28 Hay que señalar, no obstante, que los diccionarios de argentinismos tienen un antecedente inédito que data de la década de 1870 . Entre 1875 y 1879, la Academia Argentina de Letras, Ciencias y Artes trabajó en el proyecto de un Diccionario de Argentinismos que fue elaborado (pero no publicado) bajo la coordinación de Rafael Obligado, Eduardo Holmberg y Atanasio Quiroga. Entre los colaboradores se menciona a Manuel Ricardo Trelles, Fenelón Zuviría, Enrique Corona Martinez, Vicente García Aguilera y Juan María Gutiérrez. Este último, fallecido en 1878, había elaborado un vocabulario llamado "Voces usadas en Buenos Aires" que sirvió como fuente para la elaboración del Diccionario de Argentinismos. El vocabulario de Gutiérrez se publicó póstumamente, por primera vez, en el año 1886 en una revista chilena. El proyecto de Diccionario de argentinismos fue recuperado y publicado en Barcia (2006). 
en $1910^{29}$, y el Diccionario de argentinismos, neologismos y barbarismos: con un apéndice sobre voces extranjeras interesantes, de Lisandro Segovia, en $1911^{30}$.

En ambos casos, las obras se proponen como complementarias: asumen su contrastividad con la $13^{\mathrm{a}}$ edición del DRAE (1899) y con otras obras de reciente publicación: el Diccionario enciclopédico de la lengua castellana de Elías Zerolo (1895), en el caso de Segovia, y el Vocabulario rioplatense razonado de Daniel Granada (1889), El idioma del delito de Antonio Dellepiane (1894), las discusiones sobre el idioma de los argentinos entre Lucien Abeille y Ernesto Quesada y los trabajos normativos de Ricardo Monner Sans, en el caso de Garzón (Lauria 2010).

Aunque de manera diferente, el término inmigrante aparece en ambas obras: en Garzón, al nivel de la microestructura, como parte de los ejemplos ilustrativos de algunos términos y en Segovia, en el dominio de la macroestructura, como entrada autónoma con definición propia. El diccionario de Segovia está estructurado en secciones: 1) "Castellanismos y neologismos"; 2) "Americanismos"; 3) "Argentinismos"; 4) "Nombres gentilicios"; 5) "Locuciones sustantivas y otras"; 6) "Voces extranjeras"; 7) "Tribus indígenas y sus lenguas"; 8) "Fauna"; 9) "Flora"; 10) "Barbarismos";

29 Garzón, T. (1910). Diccionario argentino: Ilustrado con numerosos textos. Barcelona, Imprenta Elzeveriana de Borrás y Mestrés. Tobías Garzón (1849-1914) fue un educador y escritor argentino. Nacido en la provincia de Córdoba, luego de cursar sus estudios en el Colegio Monserrat, se dedicó a la enseñanza. Durante muchos años fue profesor de castellano en esa misma institución. Fundó el periódico La Opinión, desde el cual sostuvo la candidatura de Nicolás Avellaneda a la presidencia de la Nación en el año 1874. Fue secretario de la Universidad Nacional de Córdoba y escribió diversas obras de carácter didáctico, entre las que figura el Tercer curso de gramática castellana con número de ejercicios de ortografía, de invención y de redacción (Córdoba, La Moderna, 1898). Además, actuó como secretario y bibliotecario de la Academia Nacional de Ciencias en la ciudad de Córdoba en la década de 1870 en el marco del proyecto modernizador sarmientino, momento en el que Avellaneda se desempeñaba como ministro de Justicia y de Instrucción Pública (Lauria 2010).

30 Segovia, L. (1911). Diccionario de argentinismos, neologismos y barbarismos: con un apéndice sobre voces extranjeras interesantes, Buenos Aires, Coni. Lisandro Segovia (18421923) fue un jurisconsulto argentino nacido en la provincia de Corrientes en 1842. Estudió Derecho en la Universidad Nacional de Córdoba y fue profesor en la Universidad de Buenos Aires. Ocupó durante veintisiete años el cargo de fiscal de la Cámara de Apelaciones. Fue autor de una explicación y crítica del Código Civil y del Código de Comercio. Redactó un proyecto del Código de Procedimientos y otro del Código Penal, entre otras y diversas obras jurídicas, todas ellas a pedido del gobierno nacional entre finales de la década de 1880 y los primeros años de la de 1890. Si bien su diccionario fue publicado en 1911, bajo los auspicios de la Comisión Nacional del Centenario, la obra estuvo terminada siete años antes, es decir, en 1904, oportunidad en la que obtuvo el primer premio de la RAE en el certamen de los Juegos Florales (Lauria 2010). 
11) "Palabras interesantes portuguesas, italianas y francesas" y 12) "Refranes, frases, modismos y cláusulas". Dentro de la sección primera, Castellanismos y neologismos, se incluyen las voces comunes a la Argentina y a España, pero que en el ámbito local tienen una acepción diferente. En ese apartado aparece:

\begin{tabular}{|l|l|l|}
\hline \multicolumn{2}{|l|}{ INMIGRANTE } \\
\hline Segovia & 1911 & $\begin{array}{l}\text { (comp. A.) m. Extranjero que deja su país para } \\
\text { establecerse en otro que no es el suyo. Se dice } \\
\text { especialmente del obrero, del trabajador. }\end{array}$ \\
\hline
\end{tabular}

Esta definición expone varias cuestiones que pueden interpretarse como síntomas de un mismo clima de época. Por un lado, la primera oración ("extranjero que deja su país para establecerse en otro que no es el suyo") presenta dos particularidades:

a) el uso del sustantivo extranjero, que no estaba presente en ninguna de las obras con las cuales Segovia asume dialogar. ¿Extranjero para quién? ¿Extranjero desde cuándo: desde que deja "su país" o desde que se instala en otro? Quien deja "su país" ¿se convierte en extranjero? ¿O es extranjero desde la mirada de quienes nacieron en el país en el cual aquél se instala luego de abandonar el "suyo"? El diccionario de Zerolo, que como indicamos fue considerado por Segovia al momento de producir su obra, hace una extensa definición de este término:

\begin{tabular}{|l|l|l|}
\hline EXtranjero, RA & \\
\hline Zerolo & 1895 & $\begin{array}{l}\text { [Del lat. extrāneus, extraño, extranjero]. adj. 1. Que es o } \\
\text { viene de país de distinta dominación de aquella en que se } \\
\text { le da este nombre (...). 2. adj. y s. Natural de una nación } \\
\text { con respecto a los naturales de cualquiera otra. (...). } \\
\text { Se llama ExTRANJERA, ya sea una persona ó cosa, á la } \\
\text { que es de fuera, diferente, distinta, separada de otras, } \\
\text { extraña á ellas; aplicándola especialmente a naciones, } \\
\text { familias, profesiones, usos, etc., correspondiendo la } \\
\text { palabra a la de extraño, raro, fuera de lo común, ó sea a } \\
\text { las latinas extrāneus, alienus, alienígena, advena, exter, } \\
\text { exterus, opuestas á la de propio. (...) Y lo mismo se } \\
\text { entiende en francés, pues no sólo es ExTRANJERo entre } \\
\text { ellos el que es de otra nación, sino también el que es de } \\
\text { otro pueblo, de otra familia, de otra casa; el que es ajeno, } \\
\text { indiferente, extraño a lo que se hace, trata o dispone. } \\
\text { Todo lo extraño viene a ser allí ExTRANJERo. (...) }\end{array}$ \\
\hline
\end{tabular}


El inmigrante se carga, así, de un rasgo que lo posiciona como ajeno frente a quien enuncia, y esto subjetiva en cierto punto el discurso lexicográfico, que se supone anónimo y objetivo: una persona o familia no es extranjera per se, sino solo desde el lugar de un enunciador que ha nacido en un país diferente. Extranjero funciona, así, como un marcador deíctico que obliga a remitirse a las circunstancias de enunciación para comprender su sentido: ¿quién enuncia? ¿En qué momento? ¿Desde dónde?

b) La incorporación del sintagma "que no es el suyo" cambia el sentido del enunciado que bien podría funcionar sin ese agregado: "extranjero que deja su país para establecerse en otro". Sin embargo, la cadena completa significa algo distinto. El país de nacimiento indicaría, así, una suerte de posesión sobre ese lugar: la Argentina no es su país, sino el nuestro, no les pertenece a ellos sino a nosotros. Esto viene a reforzar la caracterización del inmigrante como extraño o "fuera de", comentada en primer término.

En sintonía con la definición de Segovia, el diccionario de Garzón define e incorpora ejemplos en algunas entradas, ubicando al inmigrante como noposeedor ni del país ni de la lengua que en él se habla:

\begin{tabular}{|l|l|l|}
\hline Cocoliche & \multicolumn{2}{|l|}{$\mid \begin{array}{l}\text { adj. Arg. Perteneciente al cocoliche. \| s. m. Arg. Lenguaje } \\
\text { híbrido que usan los extranjeros, particularmente } \\
\text { los italianos ignorantes de nuestra lengua, en el } \\
\text { que emplean voces muy incorrectas, macarrónicas y } \\
\text { heteróclitas. } \| \text { fam. Arg. Italiano que habla de este modo. } \\
\text { "Hay que reconocer entre los gérmenes corruptores que } \\
\text { obran en Buenos Aires, un factor que no es tan poderoso } \\
\text { en España: el habla popular que nace de la mezcla de } \\
\text { extranjeros, el «cocoliche», curiosa hibridización que } \\
\text { aporta el inmigrante cuando se afana en usar nuestra } \\
\text { lengua; algunos dan en imitarlo por lo mucho que } \\
\text { mueve á risa, y ha llegado á tener su literatura, ya en } \\
\text { libracos, ya en hojas periódicas, ya en los celebrados } \\
\text { dramas criollos; sus palabras podrán ser tomadas en } \\
\text { uso por la clase culta en algunas ocasiones para mejor } \\
\text { inteligencia en las indispensables relaciones con los } \\
\text { vendedores ambulantes, «changadores» y demás gente } \\
\text { que pueda usar tal jerga; pero con todo eso se está } \\
\text { muy lejos de llegar á concederles arraigo, como lo } \\
\text { demuestra el hecho de que, á pesar de constituir el } \\
\text { italiano la gran mayoría del elemento inmigrante, sean } \\
\text { tan escasas las voces y giros de esta procedencia que } \\
\text { registra nuestra habla culta" (Juan B. Selva; El Castell. } \\
\text { en Amér.; La Plata, 1906, págs. 35 y 36). }\end{array}$} \\
\hline
\end{tabular}




\begin{tabular}{|l|l|l|}
\hline \multicolumn{2}{|l|}{ Degringolade } & \\
\hline Garzón & 1910 & $\begin{array}{l}\text { (Voz franc.) s. f. fig. Arg. Salto, caída, brinco ruinoso. } \\
\text { "Después de éste, viene, como excepcional, el del año } \\
\text { anterior, con ciento sesenta mil inmigrantes, cifra } \\
\text { máxima registrada hasta ahora en períodos normales. } \\
\text { El lector comente por sí solo estas cifras, y él dirá si } \\
\text { ellas autorizan á augurar que el país se hunde, bajo } \\
\text { esta degringrolade inmigratoria". (Diario La Nación, } \\
\text { de Bs. Aires, de 28 de enero de 1902; "Ecos del día"). }\end{array}$ \\
\hline
\end{tabular}

Estos ejemplos refuerzan la definición propuesta por Segovia a partir de acepciones marcadamente valorativas (Rodriguez Barcia 2011) ya sea en el nivel de los enunciadores definidores ("voces muy incorrectas, macarrónicas y heteróclitas") o al interior de las citas de autoridad seleccionadas ("nuestra habla culta", "degringolade inmigratoria"): al inmigrante no le pertenece "nuestro país", por el contrario está provocando su hundimiento, del mismo modo en que corrompe "nuestra lengua" cuando "se afana" en usarla.

Por otro lado, retomando a Segovia, la segunda parte de la definición ("Se dice especialmente del obrero, del trabajador") incorpora un rasgo hasta el momento ausente en los artículos lexicográficos españoles: vincula el concepto de inmigrante al de "obrero" y/o "trabajador". Tal como señalamos, el apartado "Castellanismos y neologismos" incluye palabras existentes en el español peninsular, pero que a nivel local tienen una acepción diferente. Es decir: en la Argentina de comienzos del siglo XX, según Segovia, se utiliza la voz inmigrante para designar "especialmente" al obrero/trabajador de origen extranjero. ¿Qué diferencia hay entre el "obrero/trabajador" de Segovia y el "colono/labrador" de los diccionarios españoles? La figura del inmigrante que es obrero o trabajador amplía el alcance del término, haciéndolo extensivo al inmigrante urbano, propio de la realidad que Buenos Aires estaba experimentado ya desde finales de la década de 1880 , cuando las masas migratorias comenzaron a asentarse en las grandes ciudades como mano de obra industrial, y ya no únicamente en la zona de campaña. En relación con este panorama, ejemplifica Garzón:

LATIFUNDIO (pág. 275)

\begin{tabular}{|l|l|l|}
\hline Garzón & 1910 & $\begin{array}{l}\text { (Del lat. latifundium.) s. m. Arg. Campo, ó terreno } \\
\text { urbano ó suburbano, de gran extensión y de propiedad } \\
\text { de un solo individuo. }\end{array}$
\end{tabular}




\begin{tabular}{|l|l|} 
"No tenemos campesinos que mueran de hambre por \\
falta de tierra que cultivar, pero tenemos latifundios. \\
Ellos hacen que en un país inmenso y despoblado casi \\
no existe tierra disponible para el inmigrante en las \\
zonas como el litoral, dónde éste afluiría a millones, \\
literalmente á millones, si el latifundio no le impidiera \\
inundarla de tambos y de chacras". (Erasmo; "Nuevos \\
rumbos"; en La Nación, de Bs. Aires, de 5 de ag. de \\
$1906 ;$ primer art.).
\end{tabular}

El razonamiento de Garzón (los inmigrantes se hacinaron en Buenos Aires a causa de la explotación latifundista que no les concedió el acceso a la tierra) fue ampliamente retomado por gran parte de los investigadores que estudiaron la inmigración de entresiglos. Algunos atribuyen la explosión demográfica de Buenos Aires a una supuesta obstrucción del proceso colonizador a causa del surgimiento de grandes propietarios especuladores que provocaron que la inmigración "llegara a la campaña en escasa medida" (Altamirano y Sarlo 1997: 166), e incluso algunos señalan que cuando los inmigrantes llegaron, "las tierras ya tenían dueño", situación que los empujó hacia las ciudades (Onega 1969: 17). Sin embargo, si bien es cierto que durante las dos últimas décadas del siglo XIX las condiciones de acceso a la propiedad rural en la región pampeana mutaron hacia el arrendamiento (Djenderedjian 2008), hacia 1895 la provincia de Santa Fe (corazón de ese litoral mencionado por Garzón y principal distrito agroexportador del país) contaba con 360 colonias agrícolas, habitadas casi exclusivamente por población extranjera, de las cuales el 81\% (269 localidades) se habían formado a partir de 1880 (Gallo 1983). Esto significa que, al margen del tipo de condición contractual que hubieren acordado, los inmigrantes continuaron asentándose en la zona de campaña, expandiendo aceleradamente la región cerealera, sobre todo desde 1891. Es que si bien el sistema de arrendamiento hizo caer el número de colonos-propietarios, provocó de todos modos la llegada de trabajadores europeos que se incorporaron en condición de peones (Halperin Donghi 1976: 460) ${ }^{31}$.

La concentración de los extranjeros en las grandes urbes obedecería, entonces, a otros factores, entre los cuales podemos mencionar: en el plano nacional, a la diversificación de actividades económicas que comenzaron

31 Para examinar en detalle la evolución de los diferentes mecanismos de acceso a la propiedad rural y los índices poblacionales de la región pampeana hacia finales del siglo XIX, véanse especialmente Djenderedjian et al. (2010) y Martirén (2016). 
a demandar mano de obra en los sectores urbanos (puertos, comercios, obra pública), y a nivel internacional, a los cambios en las condiciones de vida en Europa que propiciaron la emigración hacia América de otro tipo de profesionales: decrecía el número de agricultores y se incrementaba la cantidad de jornaleros y artesanos que desembarcaban en Buenos Aires. Hacia 1914, los extranjeros eran el 30\% de la población total de la Argentina, pero ese porcentaje ascendía al 50,5\% en la ciudad de Buenos Aires (Devoto 2004).

De cualquier manera y al margen de las condiciones que efectivamente dieron lugar al fenómeno, la definición de Garzón deja claro que el inmigrante que se apiña en los barrios de la capital es, para la clase dirigente del 900, la contracara odiosa del proceso de despegue económico iniciado algunas décadas atrás: al comenzar el siglo XX el "elemento extranjero" ya no es un factor invisible que se asienta en la zona rural, siendo conocido en la capital solo como engranaje necesario para el modelo agroexportador. El inmigrante, a raíz de supuestos negocios latifundistas que le impiden asentarse en el litoral (argumento que hemos cuestionado), ocupa ahora el espacio público de la ciudad, camina sus calles, habla una lengua que no le pertenece y representa más de la mitad de los habitantes de Buenos Aires.

A esto deben sumarse dos aspectos, que son el producto de esa nueva redistribución demográfica y social del habitante extranjero. Por un lado, la creciente politización partidaria de los inmigrantes (urbanos, aunque no solo) que los había llevado, entre otras cosas, a formar parte de las Revoluciones Radicales de la década de 1890 provocando la caída de las autoridades constituidas ${ }^{32}$ y a organizarse en agrupaciones socialistas y anarquistas. Y, por otro lado, la fuerte sindicalización de la masa obrera fabril (mayoritariamente inmigrante) que había encabezado, durante la última década, huelgas y manifestaciones fuertemente reprimidas por las fuerzas de seguridad nacionales y provinciales.

El carácter predominantemente extranjero de las ideologías y las organizaciones obreras permitía a los grupos dirigentes una fácil y simplista traslación del conflicto de términos sociales a términos nacionales, atribuyéndolo no a la industrialización y sus consecuencias sino a la acción conspirativa de ciertos grupos de inmigrantes (Barbero y Devoto 1983). Esta situación, en la cual las elites del 900 veían amenazado el statu quo,

\footnotetext{
32 Además de la renuncia del presidente Juárez Celman en 1890, en la provincia de Santa Fe los revolucionarios llegaron a derrocar al gobernador en 1893 e instalar un gobierno de facto durante 21 días. Sobre la participación de extranjeros en los sucesos revolucionarios, véase: Gallo (2007).
} 
preparó el terreno para la sanción de dos leyes de corte nacionalista y, por añadidura, con fuerte carga de xenofobia: la ley 4.144 , conocida como Ley de Residencia, sancionada en 1902, y la Ley de Defensa Social, de 1910. La primera habilitaba al gobierno nacional a expulsar del país o a impedir el ingreso a éste, a todo aquel extranjero involucrado en "crímenes o delitos comunes" o cuya conducta "comprometiera la seguridad nacional o perturbara el orden público"33. La segunda fue una respuesta a la difusión del terrorismo: impedía el ingreso de anarquistas y permitía su expulsión, al tiempo que condenaba la apología del delito y el uso de explosivos, con duras penas que llegaban hasta la muerte ${ }^{34}$.

Retomando los diccionarios de argentinismos, vemos de qué manera estos instrumentos fijan y proyectan una imagen restringida del inmigrante, esto es, limitada por rasgos que el objeto no tenía, al menos en los anteriores instrumentos lingüísticos: a) el calificativo de distinto/extraño que reside en un país que no le pertenece, lo que otorga potestad al gobierno nacional para expulsarlo; y b) la condición de obrero o trabajador, es decir, de sujeto que, económicamente, solo posee su fuerza de trabajo. Esto pone de manifiesto la cosmovisión de una clase dirigente que buscaba dejar claro cuál era y debía ser el lugar del inmigrante en la sociedad de inicios del siglo XX: el inmigrante es y debe ser un trabajador, su lugar está en las chacras o en las fábricas y no en las calles ni en la política.

Frente a esta construcción marcadamente valorativa de la voz inmigrante, es necesario reparar en el tratamiento del término colono que, tal como apuntamos, hacia mediados del siglo XIX funcionaba de manera relativamente equivalente, en términos semánticos, a inmigrante. Los diccionarios de argentinismos no incorporan la voz colono en su macroestructura, pero sí la utilizan en ciertos enunciados definidores o en algunos ejemplos ilustrativos que se citan para definir otros términos:

\begin{tabular}{|c|c|c|}
\hline \multicolumn{3}{|l|}{ BOER } \\
\hline Segovia & 1911 & $\begin{array}{l}\text { (en holandés, paisano, agricultor), adj. Lo relativo ó } \\
\text { perteneciente á los colonos holandeses del Cabo de } \\
\text { Buena Esperanza, Orange y Transvaal. \| Ú. t. c. s. \| } \\
\text { Uno de esos colonos. }\end{array}$ \\
\hline
\end{tabular}

33 Fuente: Archivo histórico del portal Educ.ar (https://www.educ.ar/recursos/128716/ ley-n-4144-de-residencia). La Ley de Residencia fue derogada en el año 1958.

34 La Ley de Defensa Social, aunque inconstitucional, estuvo vigente hasta 1921. Por detalles sobre los conflictos sociales de la década del 10 en relación con la población inmigrante, véase Martínez Mazzola (2003). 


\begin{tabular}{|c|c|c|}
\hline \multicolumn{3}{|l|}{ MARLO } \\
\hline Garzón & 1910 & $\begin{array}{l}\text { s. m. Arg. Raspa o corazón de la mazorca ó panoja del } \\
\text { maíz. (...) } \\
\text { "Un colono de Villa Constitución, puede emplear el } \\
\text { «marlo» de maíz molido para la alimentación de los } \\
\text { vacunos y caballares, á razón de un } 20 \% \text { mezclado con } \\
\text { maíz y un } 40 \% \text { mezclado con salvado, haciendo, en } \\
\text { este último caso, una especie de masa líquida con agua } \\
\text { pura" (Diario La Nación, de Bs. Aires, de } 4 \text { de septbre. } \\
\text { de } 1902 \text {; sección "Correos"). }\end{array}$ \\
\hline
\end{tabular}

Los ejemplos, citados para definir voces no necesariamente emparentadas con el fenómeno inmigratorio, emplean el término colono para referir al habitante de las zonas rurales. Utilizado en el marco de enunciados sin valoración negativa, como en el caso de inmigrante que hemos analizado, el término colono queda, hacia el final de nuestro arco temporal, restringido para referir a un tipo específico de inmigrante: el agricultor extranjero que vive y trabaja en las zonas rurales. Y la voz inmigrante, entonces, funciona como un hiperónimo, siendo utilizada de manera más extensiva para alcanzar también a aquellos que se instalaron en los espacios urbanos.

\section{RECAPITULACIÓN Y COMENTARIOS FINALES}

De manera general, este análisis nos permitió comprender el modo en que las condiciones de producción, ya sea inmediatas o en sentido amplio, han determinado gran parte de las modificaciones históricas que experimentó el campo semántico de la inmigración en la lexicografía del español. En ese sentido, retomamos la premisa planteada inicialmente al asumir que el diccionario monolingüe encarna un doble fenómeno: por un lado, es el síntoma de una época, a la cual refleja y de la cual se nutre, y por otro es un instrumento de reproducción de un estado de cosas, al presentarse como la descripción "objetiva" y "neutral" del lenguaje, que queda despojado, así, de su contenido histórico e ideológico.

En lo particular, el relevamiento diacrónico de la macro y microestructura de las obras analizadas puso de manifiesto las transformaciones que la voz inmigrante y los lexemas semánticamente próximos fueron experimentando en el discurso lexicográfico, transformaciones que pueden agruparse en tres 
etapas. La primera, que va desde 1726 hasta 1843 , comprende el período temprano de definiciones: la inmigración y el inmigrante aún no existen en el registro lexicográfico. Sí se registran las voces emigrar y emigrado, las cuales hacia el final de la etapa quedan ligadas a la persecución política que afectaba a España durante las primeras décadas del siglo XIX: un emigrado era un perseguido político. La segunda etapa comprende desde 1855 hasta 1899: la inmigración y el inmigrante aparecen como voces, en parte como producto de la proliferación de diccionarios de autor. El proceso inmigratorio se vincula con el fenómeno de la colonización agrícola que comienza a producirse desde mediados del siglo XIX, particularmente en Argentina. Finalmente, la tercera es la etapa del Centenario argentino: hacia 1910, en el marco de un proyecto institucional conmemorativo de un hito central dentro de las "gestas patrias", la lexicografía local introduce una definición de inmigrante fuertemente ligada a las condiciones de producción y al clima de época. Los diccionarios del Centenario incorporan una dimensión moral, sus definiciones resultan aleccionadoras y definen un "deber ser": el inmigrante está en un país que no le pertenece y por tanto debe limitarse a su lugar de trabajador, ya sea urbano o rural.

\section{REFERENCIAS BIBLIOGRÁFICAS}

Altamirano, Carlos y Beatriz Sarlo. 1997. La Argentina del Centenario: campo intelectual, vida literaria y temas ideológicos. Ensayos argentinos. De Sarmiento a la Vanguardia. Buenos Aires: Ariel.

ANDERSON, BENEDICT. 1993. Comunidades imaginadas. Reflexiones sobre el origen y la difusión del nacionalismo. México: Fondo de Cultura Económica.

Arnoux, ELVIRa. 2008. Los discursos sobre la nación y el lenguaje en la formación del Estado (Chile, 1842-1862). Estudio Glotopolítico. Buenos Aires: Santiago Arcos.

y José Del Valle. 2010. Las representaciones ideológicas del lenguaje. Discurso glotopolítico y panhispanismo. Spanish in context 7(1): 1-24.

Auroux, Sylvain. 1992. A revolução tecnológica da gramatização. Trad. Eni P. Orlandi, Campinas: Editora da UNICAMP.

Barbero, María Inés y Fernando Devoto. 1983. Los nacionalistas. Buenos Aires: Centro Editor de América Latina.

Barcia, Pedro Luis. 2006. Un inédito diccionario de argentinismos del siglo XIX. Buenos Aires: Academia Argentina de Letras.

Devoto, Fernando. 2004. Historia de la inmigración en la Argentina. Buenos Aires: Sudamericana.

DJendeREDJIAN, Julio. 2008. La colonización agrícola en Argentina, 1850-1900: problemas y desafíos de un complejo proceso de cambio productivo en Santa Fe y Entre Ríos. América Latina en la Historia Económica 15 (2): 129-157. 
, Sílcora Bearzotti y Juan Luis Martirén. 2010. Historia del capitalismo agrario pampeano: Expansión agrícola y colonización en la segunda mitad del siglo XIX. Buenos Aires: Teseo.

Fuentes, Juan Francisco. 2002. Imagen del exilio y del exiliado en la España del siglo XIX. Ayer: Revista de Historia Contemporánea 47: 35-56.

Gallo, Ezequiel. 2007. Colonos en armas. Buenos Aires: Siglo XXI.

1983. La pampa gringa. La colonización agrícola en Santa Fe (1870-1895). Buenos Aires: Sudamericana.

Guimerá Peraza, Marcos. 1996. Don Elías Zerolo, el intelectual puro (1848-1900). Anuario de Estudios Atlánticos 42: 659-702.

Halperin Donghi, Tulio. 1976. ¿Para qué la inmigración? Ideología y política inmigratoria y aceleración del proceso modernizador: el caso argentino (1810-1914). Jahrbuch für Geschichte von Staat, Wirtschaft und Gesellschaft Lateinamerikas, pp. 437-489.

Lara, Luis Fernando. 1997. Teoría del diccionario monolingüe. México: El Colegio de México.

LaURia, Daniela. 2011. Apuntes para una historia de la producción lexicográfica monolingüe en la Argentina: etapas del proceso de diccionarización y modalidades diccionarísticas entre 1870 y 1910. Boletín de Filología, Universidad de Chile, № 1, T. XLVI: 105-151.

2010. Análisis del discurso lexicográfico: lengua y nación en los diccionarios de argentinismos (1870-1910). Tesis para optar al grado de Magíster en Análisis del Discurso, Universidad de Buenos Aires.

2003. ¿Cuestión social o cuestión nacional? Los debates en torno al naciente movimiento obrero. En Villavicencio, Susana. (ed.). Los contornos de la ciudadanía: nacionales y extranjeros en la Argentina del Centenario. Buenos Aires: Eudeba.

Martínez Mazzola, Ricardo. 2003. ¿Cuestión social o cuestión nacional? Los debates en torno al naciente movimiento obrero. En Susana Villavicencio (ed.). Los contornos de la ciudadanía: nacionales y extranjeros en la Argentina del Centenario. Buenos Aires: Eudeba.

MARTIRÉN, JUAN LUIS. 2016. La transformación farmer: colonización agrícola y crecimiento económico en la provincia de Santa Fe durante la segunda mitad del siglo XIX. Buenos Aires: Prometeo.

Medina López, Javier. 2007. Elías Zerolo (1848-1900) y la labor de la Real Academia Española. Revista de filología española 87(2): 351-371.

Nunes, José HorTa. 2006. Dicionários no Brasil: análise e história do século XVI ao XIX. Campinas: Pontes Editores.

Onega, Gladys. 1969. La inmigración en la literatura argentina. Buenos Aires: Galerna.

Orlandi, Eni Pulcinelli. 2015. Análise de discurso. Princípios e procedimentos. Campinas: Pontes Editores.

Rodríguez Barcia, Susana. 2012. El análisis ideológico del discurso lexicográfico: una propuesta metodológica aplicada a diccionarios monolingües del español. Verba 39: $135-159$.

2011. Un mundo a su medida. La construcción de la realidad en los últimos diccionarios de la RAE. En Senz, S. y M. Alberte (eds.). El dardo en la Academia. Esencia y vigencia de las academias de la lengua española. Vol. II. Barcelona: Melusina. 